\title{
Fatality prediction model for motorcycle accidents in Malaysia
}

\begin{abstract}
This paper involves building a fatality predictive model for motorcycle accidents data in Malaysia. The number of registered motorcycles in Malaysia has increased four-fold compared to the last 20 years. Thus, the motorcycle accidents rate and fatality rates among riders and pillion in Malaysia has also increased dramatically. However, results show that when taken into account the numbers of fatalities per 10,000 registered motorcycles, the fatality rate shows a decreasing trend starting from 1996 onwards. The motorcycle accident data for the period of 1996 to 2010 was analyzed using Smeedô Law and regression method. The results show that regression method approach gives better estimates of fatality rate than Smeedôs equation.
\end{abstract}

Keyword: Motorcycle accident; Smeed's law; Regression method; Predictive model 